\title{
As concepções do conselheiro real Polônio em quatro adaptações de Hamlet para os quadrinhos
}

Thiago Martins Prado

Resumo: Centrando-se na figura do conselheiro real da peça Hamlet, de Shakespeare, o estudo apresenta as variações nas versões de quatro HQs na reelaboração da personagem Polônio: a adaptação de Grant e Mandrake (1990), influenciada pela escola de Brandywine; a adaptação da Equipe East Press (2013), um mangá que demonstra um cuidado com a distribuição das personagens mudas em cena para afirmar uma pesquisa consistente do texto shakespeariano; a adaptação de Vieceli (2011), um mangá que se centra no vestuário para adotar uma atmosfera tecnológico-futurística, e a adaptação de Srbek e Shibao (2013), com foco maior nas posições corpóreas em cena.

Palavras-chave: tradução intersemiótica; quadrinhos; Hamlet; Polônio.

Abstract: The conceptions of the real counselor Polonius in four comic adaptations of Hamlet - Focusing on the figure of the royal counselor of the play Hamlet by Shakespeare, the study will present changes in versions of four Comics on reworking the character Polonius: the adaptation of Grant and Mandrake (1990), influenced by the school of Brandywine; the adaptation of the East Press Team (2013), a manga that demonstrates an attention on the distribution of the mute characters in scene to assert a consistent search for the Shakespearean text; the adaptation of Vieceli (2011), a manga that focuses on clothing to incorporate a technological-futuristic atmosphere, and the adaptation of Srbek and Shibao (2013), with a greater focus on bodily positions on the scene.

Keywords: intersemiotic translation; comics; Hamlet; Polonius.

\section{Introdução}

A tradução intersemiótica de uma personagem do gênero dramático para os quadrinhos parece ser facilitada pela realização do texto teatral em cena. No palco, 
um artista de HQ pode estudar dinâmicas diretamente ligadas ao uso da imagem: gestos, pausas sugestivas de falas, entonações de vozes e expressões faciais, que denotariam uma valência emocional significativa para o entendimento do conceito da personagem. Entretanto, essa facilidade é mera aparência caso se entenda a distância entre essas duas linguagens: a do gênero dramático busca uma interpretação do texto para dotá-lo de movimento imediato como resultado inerente ao processo de causalidade - as personagens, entre falas e ações, podem gradativamente consolidar ou complexificar suas características no decorrer das encenações; o gênero dos quadrinhos ativa seu movimento com uma série de quadros estáticos, em que a evolução do caráter da personagem do gênero dramático é substituída por uma imagem com alto poder de síntese e que possa concentrar diversas informações de comportamentos, de gestos e de distribuição de espaços num único quadro.

No caso de o artista de quadrinhos prender-se meramente ao texto dramático para pesquisar a realização da sua narrativa gráfica, ele terá que forjar uma interpretação condensada e bem mais econômica em comparação a um diretor de teatro, que conduz uma série de atuações com nuances variáveis demonstrando o diferencial da montagem da peça. Enquanto o diretor possui maior liberdade para testar detalhes nas ações e no caráter das personagens, o artista de HQ tenta manter a coerência da narrativa gráfica desenhando a realidade das formas físicas de cenário e de corpos de personagens e, ao mesmo tempo, adotando cortes estratégicos de falas para a dinâmica de balões. O diretor da peça teatral, por exemplo, apresenta a vantagem de dotar uma valência emocional ou uma variação comportamental em uma personagem de fala a fala, no caso do quadrinista, muitas falas das personagens, além de frequentemente resumidas, aparecem de forma simultânea nos quadros como um princípio de economia do formato das narrativas gráficas.

Levando em consideração as releituras, as adaptações, os textos críticos ou as interpretações já encenadas do texto dramático, o artista de quadrinhos pode envolver-se numa situação ainda mais tensa para a construção de sua narrativa gráfica. Como ilustração, se um artista de HQ resolve escolher Hamlet, o texto dramático mais discutido de William Shakespeare, a fim de realizar uma tradução intersemiótica para os quadrinhos, será muito improvável que tal artista consiga manter-se invulnerável à quantidade infinitesimal de fortuna crítica e de interpretações a respeito da peça. É óbvio que aqui também se pode pensar que as múltiplas direções críticas e interpretativas dadas ao texto dramático fornecem interessantes materiais de consulta para a construção dos quadrinhos. O que indica ser uma vantagem, no final das contas, como é no caso de Hamlet, torna-se uma questão problemática a ser enfrentada, pois muitos dos textos críticos ou das interpretações propõem sentidos diametralmente diferentes, difusos ou irreconciliáveis em relação às motivações das personagens.

A atividade de elaborar um conceito convincente à personagem Polônio e de sustentá-lo em forma de desenho e com a tipologia dos balões deve ser inicialmente encarada com esse mesmo grau de dificuldade de que se tratou até então. Sem que 
se considere a interpretação fílmica ou teatral, que também é variável em relação à postura da personagem Polônio, a crítica literária especializada que discute o conceito da personagem Polônio aponta direções diversas a respeito do conselheiro real: a) Amora (2006, p.280) destaca o caráter de Polônio como desastrado, bisbilhoteiro, imprudente e antipático; b) Vygotsky (1999, p.127) atribui a Polônio o papel de vítima do fim inevitável e catastrófico da peça em meio ao ambiente funesto alimentado pelo estado de espírito hamletiano e pelo assassinato real; c) Bloom (2004, p.104-105) impõe a Polônio uma condição de personagem periférico, tal como Guildenstern ou Rosencrantz, a funcionar como um mero desenvolvedor do caráter crítico ou cômico-irônico do príncipe Hamlet; d) Jones (1970, p.121-122 e p.133-135) compreende a personagem Polônio por meio do processo de decomposição do arquétipo paterno pelo príncipe Hamlet; e) Frye (1992, p.116) enfatiza a metonímia que Polônio representa como pai assassinado que precisa ser vingado, assim como acontece com o pai de Hamlet, etc.

O estudo do conceito de uma personagem de texto dramático nessas condições de proliferação crítica e em meio à frequente remontagem e releitura da peça é, por si mesmo, uma atividade desgastante e demorada. No caso da tradução intersemiótica para os quadrinhos, sérias escolhas precisam ser feitas para que o princípio de economia de quadros e de falas possa ser respeitado sem que isso prejudique o enredo ou a concepção básica das personagens. Nesse sentido, as adaptações para os quadrinhos da peça shakespeariana realizadas por Grant e Mandrake, por Vieceli, por Srbek e Shibao ou pela Equipe East Press, no intuito de superarem os limites da linguagem das narrativas sequenciais e de atender às suas peculiaridades, selecionaram informações textuais e extratextuais, cortaram passagens ou estabeleceram acréscimos que forjaram, eliminaram ou destacaram determinados aspectos em cada personagem apresentado - assim também ocorrendo com Polônio, a personagem aqui estudada.

Para compreender as semelhanças e as diferenças de interpretações entre as quatro adaptações citadas, duas situações foram investigadas com maior cuidado: a) a utilização de estereótipos para a construção da imagem de Polônio; e b) a interpretação dos artistas de HQ a respeito do papel de pai de Polônio. Essas situações exemplificam escolhas, cortes ou acréscimos realizados nas HQ como elementos de originalidade ou de distância em relação ao texto original e à concepção da personagem Polônio.

\section{A construção da imagem de Polônio}

Conforme Will Eisner (2005, p.22-24), o uso de estereótipos ou de simbologias, compondo ou associando-se, respectivamente, à personagem dos quadrinhos é um artifício de economia narrativa comum nesse gênero. O teórico e artista dos quadrinhos Eisner (2005, p.20) defende que as imagens das narrativas gráficas apresentam limitações 
para exprimir abstrações com facilidade e que a estereotipia ou os simbolismos acabam por traduzir efeitos mais absolutos, diretos e também mais específicos para a constituição das personagens.

As quatro adaptações, inevitavelmente, utilizam-se desses recursos para a composição do conselheiro real Polônio. É possível até se constatarem algumas coincidências em relação à escolha dos artistas de $\mathrm{HQ}$ envolvidos nesse estudo. A marca de sabedoria e maturidade, por exemplo, é indicada pela barba longa da personagem nas versões de Grant e Mandrake (Fig.1) e da Equipe East Press (Fig.2) ou ainda pela barba branca nessas duas e mais na adaptação de Srbek e Shibao (Fig.3).
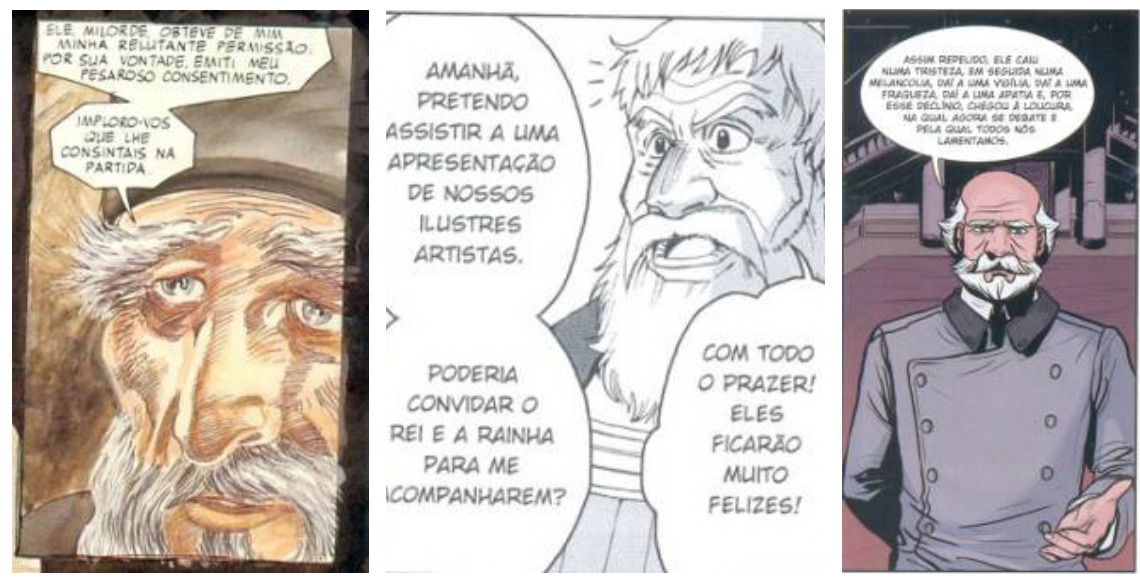

Fig.1. Adapt. Grant e Mandrake, p.5. Fig.2. Adapt. East Press, p.71. Fig.3. Adapt.Srbek e Shibao, p.23

A variação para uma barba mais aparada que aparece na adaptação de Srbek e Shibao surge em consonância com a escolha de um vestuário e de uma atmosfera mais modernos em comparação às adaptações de Grant e Mandrake e da Equipe East Press. Enquanto essas duas adaptações conservaram uma ambiência mais próxima do período medievo, respeitando a cronologia imposta pela peça e pela lenda que a fomenta, a adaptação de Srbek e Shibao apresenta uma monarquia com mais aproximações do período limiar da modernidade em seu vestuário e cenário, creditando ligações entre as reflexões shakespearianas à invenção do homem moderno num momento posterior.

Tratando-se do quadrinho de Emma Vieceli, o distanciamento temporal do período medieval sugerido pelo enredo shakespeariano é ainda maior. Vieceli concebe a adaptação do seu Hamlet no futuro e em uma atmosfera cibernética. Da barba, portanto, só sobra um bigode - a esse respeito é importante relatar que Polônio, como versão futurista do sábio, é o único a conservar pelos no rosto em toda a HQ de Vieceli. No entanto, como uma das marcas comuns de autoridade sugerida pelos desenhos de Grant e Mandrake (Fig.4) e pelos de Vieceli (Fig.5), ocorre a posse de chapéu. 

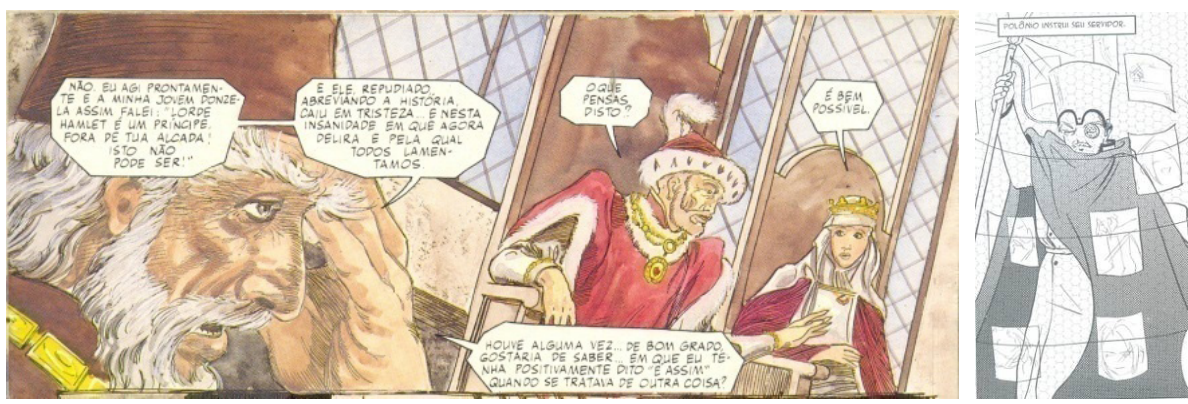

Fig. 4. Adapt. Grant e Mandrake, p.17. Fig. 5. Adapt. Vieceli, p.58.

Quanto ao vestuário do conselheiro Polônio, é interessante notar que o quadrinho de Emma Vieceli associa a manta de aspecto mais conservador e de recordação medieva a uma versão de roupa mais atual com costura e botões (Fig.5). Em verdade, a perspectiva futurista de Vieceli sintetiza um diálogo entre antigo e moderno - próprio do ciclo da moda. E isso também acontece se for observado um dos itens de composição dessa personagem: o bastão. O bastão de Polônio relembra a autoridade de sábios desde Moisés, entretanto tal instrumento também é o que permite a exibição e a gravação de hologramas. Em relação à postura corporal, o mangá de Vieceli (Fig.8) e o da Equipe East Press (Fig.6 e 7) repetem um trejeito performático e significativo para a construção do conselheiro Polônio. A introdução da tosse como preparação dramática de um discurso mais sério, representativo ou de uma defesa de opinião mais contundente frente à autoridade real acontece tanto na adaptação da Equipe East Press quanto na de Emma Vieceli.
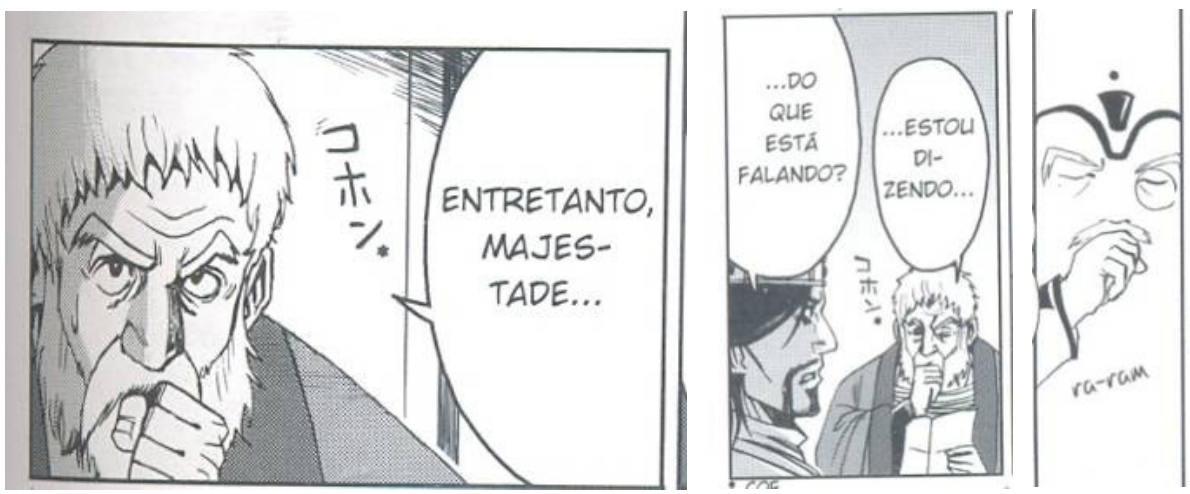

Fig. 6. Adapt. East Press, p.59. Fig. 7. Adapt. East Press, p.62. Fig. 8. Adapt. Vieceli, p.84

Embora elementos compositivos possam aparecer em coincidência nas adaptações, é preciso levar em conta que elas, segundo Pina (2014, p.74-75), são apropriações da obra original e que, portanto, os quadrinistas adaptadores tornam-se intérpretes do texto fonte e 
é aqui que Patrícia da Costa Pina defende a complexidade e densidade das adaptações de obras literárias para o gênero quadrinhos. As adaptações também são recriações em que se relacionam material cultural do autor do texto original e entendimento e codificação sociocultural do adaptador. Ademais, a estudiosa não enxerga na imagem do quadro das narrativas gráficas um mero resumo da descrição do texto a ser adaptado - ela defende que a imagem intensifica a significação dada ao texto.

A partir dessa consideração de Pina, podem-se investigar algumas peculiaridades nas escolhas de cada quadrinho como uma forma de reinterpretação e recriação do conselheiro Polônio. A obsessão pela fala performática do conselheiro real é indicada de forma diferente em cada uma das adaptações por exemplo. Na narrativa gráfica de Steven Grant e Tom Mandrake, a boca aberta ou a multiplicação de balões na personagem Polônio sinalizam o caráter teatral da fala do conselheiro (Fig.9, 10, 11 e 12).
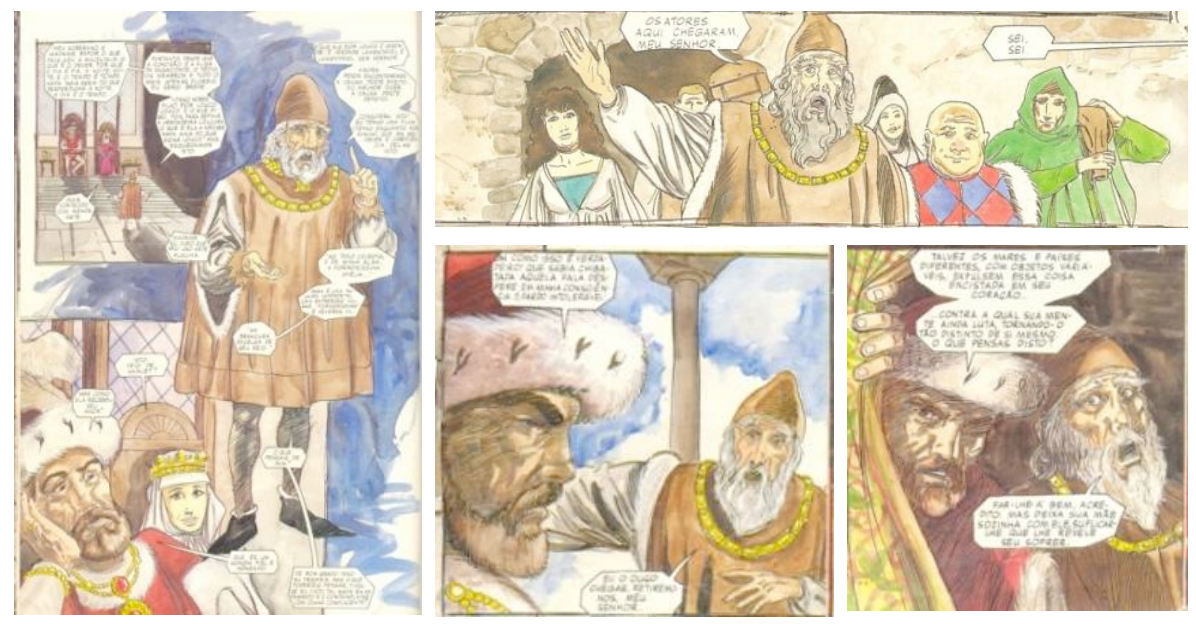

Fig. 9. Adapt. Grant e Mandrake, p.16. Fig. 10. Adapt. Grant e Mandrake, p.23.

Fig.11. Adapt. Grant e Mandrake, p.25. Fig.12. Adapt. Grant e Mandrake, p.27.

No último quadro em que Polônio aparece na adaptação de Grant e Mandrake, a boca aberta surge na cena da sua morte como uma forma de substituição do último gesto performático do conselheiro registrado na peça shakespeariana, a fala de Polônio sobre o seu próprio ato de morrer (Fig.13): “Oh, me mataram!” (SHAKESPEARE, 2003, p. 166). 

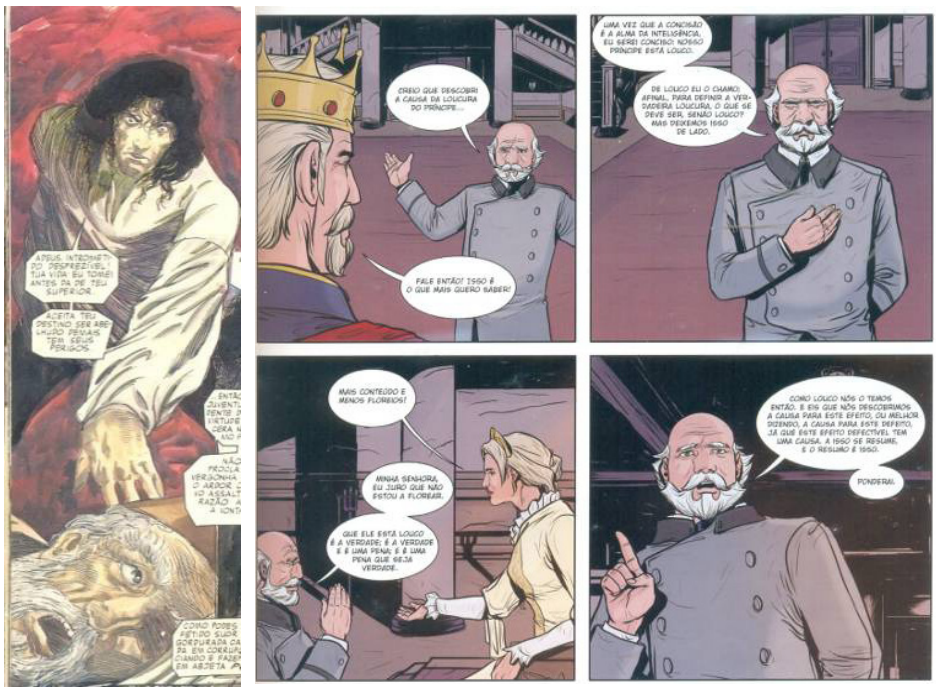

Fig.13. Adapt. Grant e Mandrake, p.34. Fig.14. Adapt. Srbek e Shibao, p.23

Diferentemente, a adaptação de Srbek e Shibao não faz tanto uso da técnica da multiplicação dos balões em um só quadro - o que obriga tal HQ a aumentar a participação de Polônio nos quadros e a realizar um resumo maior de suas falas. Com isso, ocorrem duas consequências bem diretas na construção dessa personagem nos quadrinhos de Srbek e Shibao. A primeira delas é que, por causa da necessidade maior de colocarem em quadros sequenciais o conselheiro Polônio em suas falas mais longas, os quadrinistas exploraram as posturas corporais da personagem, suavizando o caráter verborrágico e enfatizando a dimensão performática de suas falas (Fig.14). A segunda delas é que essa manutenção da personagem em diversos quadros sequenciais obrigou os quadrinistas, por economia de edição, a eliminarem cenas importantes em que se caracterizava a personagem Polônio como figura paterna: as falas com o filho Laertes ou sobre o mesmo simplesmente foram eliminadas, e a orientação de afastamento inicialmente dada à filha Ofélia também foi subtraída. Ainda que tais cenas estejam retiradas, essa adaptação, em decorrência das escolhas de enquadramento, possui a maior porcentagem de ocorrências da personagem Polônio por quadro.

Contrastes quanto à construção do conceito do conselheiro real entre as duas adaptações de quadrinhos em cores de Hamlet ocorrem nitidamente. Em mais uma ilustração, na cena de explicação de Polônio a respeito da loucura do príncipe Hamlet dada ao rei Cláudio e à rainha Gertrudes, o dedo levantado para o alto como uma performatização do domínio de um saber profundo que precisa ser explicitado surge em ambas adaptações como uma aproximação estereotipada que alimenta a imagem do orador, entretanto o efeito da cena é diverso para cada uma delas. Na adaptação de Grant 
e Mandrake, enquanto o rosto inclinado do rei dá a impressão de pouca credibilidade do discurso de Polônio, sugerindo uma comicidade advinda de uma fala que conserva uma pseudossabedoria a ser ridicularizada (Fig.9), na adaptação de Srbek e Shibao, a fala de Polônio ocorre num ambiente de seriedade em que não acontecem quaisquer sinalizações de contestação ou de ridicularização (Fig.14). Ademais, quanto à cena da morte de Polônio, os conceitos quanto à personagem também se mostram opostos entre essas duas adaptações: enquanto Grant e Mandrake direcionam o foco da ação de morrer como um ato teatral comandado pela própria personagem e de sua última fala na peça (Fig.13), Srbek e Shibao concentram-se na descrição de Hamlet sobre a morte de Polônio, tornando a sua expressão facial uma máscara mortuária, que se apaga distante do drama agitado da vida (Fig.15) - as cenas da discussão de Hamlet com a rainha e da morte de Polônio, ainda que ocorram paralelas, parecem estar em planos muito distintos em que o teatro da vida e o silêncio da morte não se comunicam. Paradoxalmente, ao seguir a orientação da fala do príncipe sobre a morte do conselheiro, Srbek e Shibao desviam do padrão de utilização de traços para a expressão facial de Polônio e tornam esse o momento mais trabalhado na composição da emoção por meio do rosto em relação à personagem Polônio: "Na verdade, este conselheiro está agora muito quieto, muito discreto e muito sério, ele que em vida foi um patife tolo e tagarela." (SHAKESPEARE, 2003, p.180).

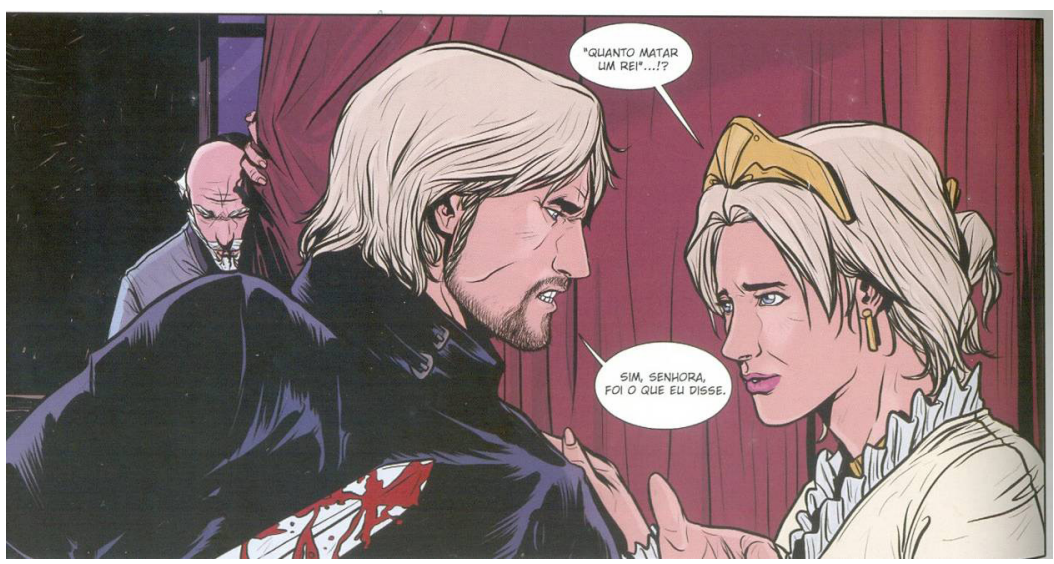

Fig 15-Adap. Srbek e Shibao, p.42

As adaptações em mangá também realizam estratégias distintas para a descrição do caráter da personagem Polônio. Na adaptação da Equipe East Press, as falas de Polônio poluem um quadro específico. Embora a personagem não apareça no quadro, o volumoso discurso é uma presença física a espremer os filhos. Em meio a tanto palavrório a ocupar os espaços do quadro, Ofélia enrubesce, e Laertes sua no rosto apreensivo - a Equipe East Press constrói uma oportunidade de inserir a comicidade própria de muitos mangás na peça 
hamletiana sem que se deturpe a mistura de gêneros entre tragédia e comédia que, por vezes, o dramaturgo Shakespeare também realiza em suas obras (Fig.16). No caso da versão de Emma Vieceli, a história foi recriada para ocupar um contexto futurista, cibernético e distópico, e isso, invariavelmente, também repercute na composição da personagem Polônio. A fala frequente do conselheiro real é simbolizada pelo microfone auricular agarrado à boca (Fig.17). Na cena da morte de Polônio, num close-up realizado na face dele, o sangue saído da boca sinaliza para a fala excessiva e intrometida do conselheiro como um dos motivos de seu assassinato. Nesse mesmo quadro, o monóculo, símbolo de sabedoria na versão de Vieceli, aparece rachado com a queda do morto (Fig.18) - com o falecimento de Polônio, extinguem-se também o conhecimento estratégico e a arte da persuasão discursiva elaborados em tempos anteriores.
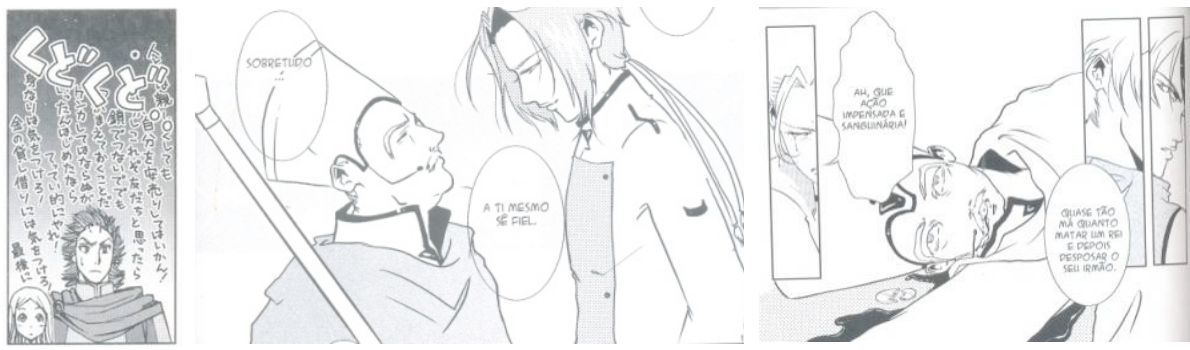

Fig.16. Adapt. East Press, p.34. Fig.17. Adapt. Vieceli, p.45. Fig.18. Adapt. Vieceli, p.132

Outras variáveis imprevistas de composição da personagem Polônio surgem nessas quatro adaptações. Na versão de Grant e Mandrake, um punhal à cintura de Polônio revela um caráter de excessiva prudência e proteção em uma cena em que ele acaba de tecer conselhos ao filho Laertes, antes de partir para a França e que se prepara para orientar a filha Ofélia, a fim de protegê-la da paixão avassaladora da juventude (Fig.19). Na narrativa gráfica da Equipe East Press, a diferença de estatura entre Polônio e o rei Cláudio, com o conselheiro bem menor que a autoridade real, sugere a ideia de fraqueza física, de falta de imponência para a personagem (Fig.20). Na HQ de Emma Vieceli, como já foi analisado, a substituição de barba por bigode preserva o ambiente futurista criado pela adaptadora, mas, de igual modo, mantém uma marca de sabedoria antiga quando se observa que nenhuma das demais personagens possui pelos nos rostos. Em outro momento, Vieceli apresenta um quadro em que fica evidente o orgulho de Polônio quanto à declaração de seu passado como ator - o sorriso do conselheiro nesse momento do quadro deixa clara a origem do prazer pelo jogo da representação no palco social (Fig.21). Com essa interpretação de Vieceli, Polônio e Hamlet tornam-se antípodas. Enquanto o conselheiro alegra-se pelo ato de fingir e de encenar, montando suas performances para alcançar mais prestígio junto à autoridade real, o príncipe busca uma verdade como prova de um crime utilizando-se do fingimento para destituir o rei Cláudio. 

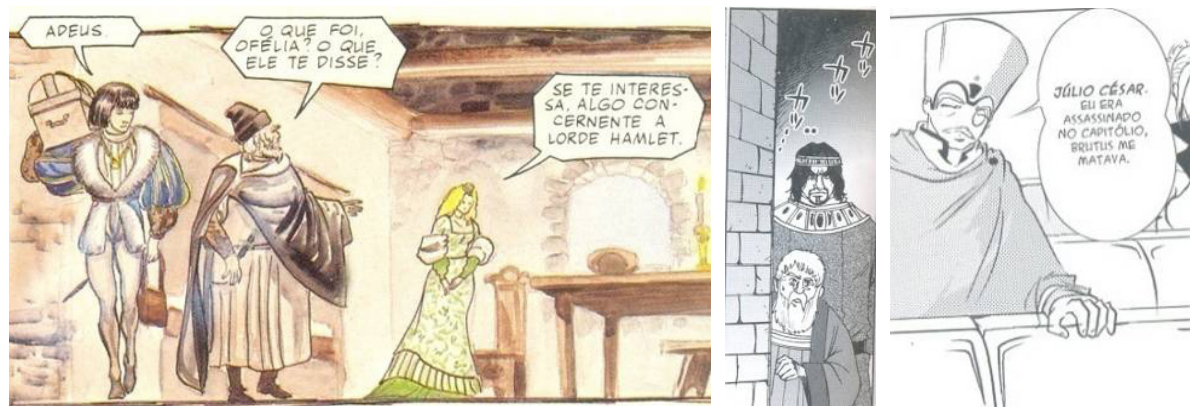

Fig.19. Adapt. Grant e Mandrake, p.10. Fig.20. Adapt. East Press, p.98. Fig.21. Adapt. Vieceli, p.108.

A adaptação de Srbek e Shibao, dentre todas analisadas, é a que menos busca um traço dramático e emocional na composição do rosto do conselheiro real Polônio, todas as modificações são por demais sutis e denotam um padrão de rosto e de emoção bem repetidos, e isso interfere no conceito elaborado para essa personagem na HQ. Com essa estratégia, Srbek e Shibao apresentam uma personagem que preserva um controle demasiado sobre as suas emoções e dedica-se a ocultá-las também. Essa máscara de serenidade sugere a descrição de Walter Benjamin (1984, p.117-121) a respeito do saber amargo que o intrigante possui a fim de não se envolver com as paixões da vida para que não adote comportamentos imprudentes e para poder manobrar as paixões dos outros. O uso desta técnica, de outro modo, retira a comicidade de algumas cenas manifesta por essa personagem e limita, igualmente, a postura descompassada de alguns comportamentos de Polônio em determinadas situações. Como solução intermediária para a demonstração de alguns exageros por parte de Polônio, Srbek e Shibao, em duas situações, utilizam quadros em que posições corporais da personagem esboçam certa desmedida. O primeiro quadro retrata a euforia de Polônio por introduzir aos reis uma versão sobre o motivo da loucura do príncipe Hamlet, que também pode lhe dar certa vantagem junto aos favores reais (Fig.22). Como reforço de uma ação desmedida, os cortesãos Rosencrantz e Guildestern parecem surpresos com a pressa de Polônio em chegar aos reis. O segundo quadro retrata a comunicação de Polônio ao príncipe Hamlet sobre a presença de atores no reino (Fig.23). A postura exagerada na presença do príncipe sugere que a tentativa de Polônio em servir os mais poderosos é um projeto obsessivo para requerer constantes privilégios que, em determinados momentos, contradiz o cálculo prudente de sua mente. 

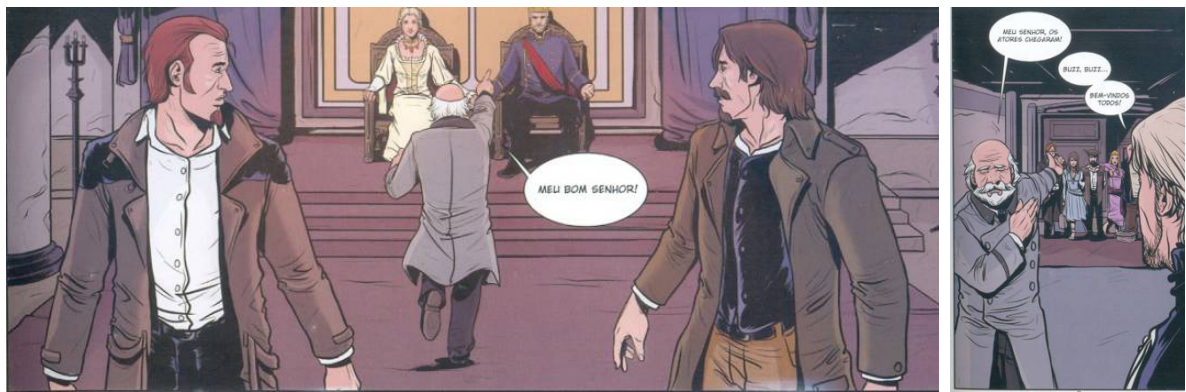

Fig.22. Adapt. Srbek e Shibao, p.23. Fig.23. Adapt Srbek e Shibao, p.31

\section{O papel de pai de Polônio}

Uma das características destacadas por Northrop Frye (1992, p.117) para a composição da personalidade do conselheiro Polônio é o seu excessivo controle sobre os filhos. Contraditoriamente, a adaptação de Srbek e Shibao reduz todo o poder de atuação paterna do conselheiro Polônio à sua missão de conselheiro real. Por um lado, os quadrinistas retiram as cenas de interlocução com o filho Laertes e de aconselhamento inicial à filha Ofélia; por outro lado, o desenho facial sereno de Polônio ao falar com Ofélia não sugere qualquer sentimento de maior afeto ou paternalidade. Ao contrário disso, o seu gesto de levar a mão ao queixo dá ao leitor a impressão de que pode levar vantagens com a versão da história sobre a loucura de Hamlet relatada por Ofélia (Fig.24).
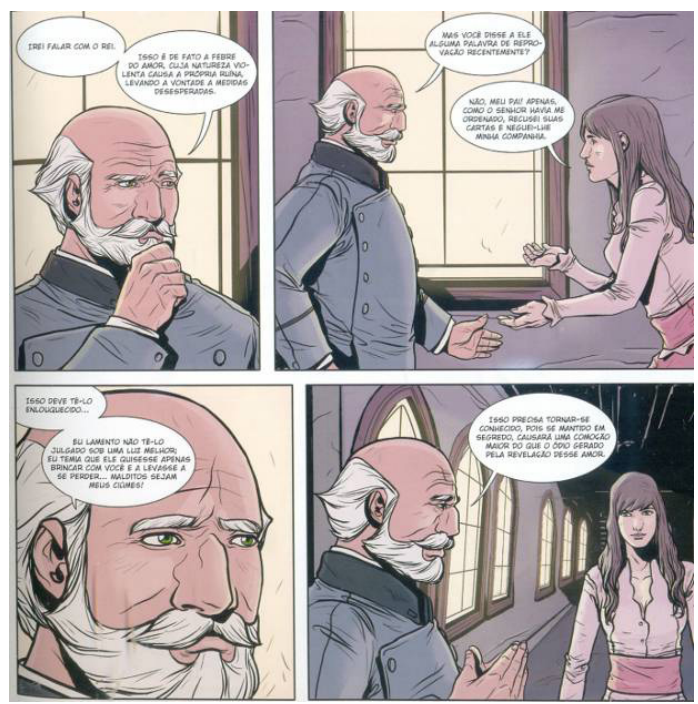

Fig.24. Adapt. Srbek e Shibao, p.21. 
Especificamente, para a representação mais absoluta da atitude paterna descrita por Frye para a referida personagem, as outras três adaptações quadrinísticas utilizam um mesmo gesto: o dedo em riste (Fig.25, 26, 27 e 29). É interessante notar que, embora esse detalhe da linguagem corporal coincida para essas adaptações de HQs a fim de denotar a intenção de domínio em relação às ações dos filhos, nos quadros em que ocorre o dedo levantado de Polônio, as expressões faciais do conselheiro sugerem, sutilmente, valências emocionais diversas em cada adaptação, que fazem variar a conceituação da personagem. Tal como explica Scott McCloud (2008, p.103), embora a linguagem corporal nos quadrinhos sustente-se como um ato-resposta referente às ocasiões variadas vivenciadas nas HQs (base situacional), as expressões faciais desvelam, com mais propriedade, as emoções que preenchem o caráter das personagens. A partir dessa distinção no entendimento da linguagem corporal e da expressão facial oriunda da orientação de McCloud, pode-se observar como um mesmo gesto (o dedo em riste nas três adaptações), que se origina da situação do aconselhamento dos filhos, é interpretado de forma completamente diferente pela Equipe East Press, por Emma Vieceli ou por Tom Mandrake - o que fica nítido pelas sugestões apresentadas pelas expressões faciais exploradas por cada ilustrador.

A Equipe East Press enfatiza o caráter autoritário que Polônio exerce nos filhos quando elege a atribuição de um olhar fixo do conselheiro aos seus interlocutores e a conservação de um semblante ríspido. No caso da fala dirigida à filha Ofélia, o retrato da repreensão severa é traduzido por alguns elementos plásticos: o contorno do balão e a tipografia em negrito e em fonte maior de fala do conselheiro marcam o volume e a gravidade das imposições de Polônio (Fig.26). Em relação à expressão facial, a personagem, nesse mesmo quadro, atinge uma combinação enraivada prevista por Scott McCloud (2008, p.9293): o músculo corrugador franze o cenho somado à elevação de pálpebra assim como os músculos levator labii superioris, depressor labii inferioris e risorius produzem uma boca mais enquadrada de predador.
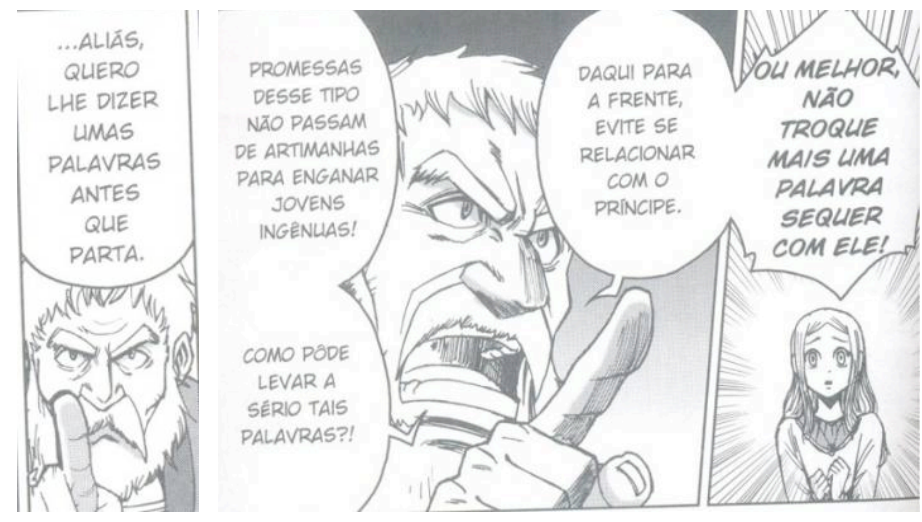

Fig.25. Adapt. East Press, p.34. Fig.26. Adapt. East Press, p.36. 
Nos quadrinhos de Emma Vieceli, os olhos fechados da personagem Polônio enquanto tece orientações ao filho Laertes denota um conceito totalmente diverso daquele utilizado pela Equipe East Press. O perfil do conselheiro de olhos fechados resulta numa impressão de soberba sabedoria. A fala da personagem parece vir de um conhecimento ancestral, guardado na interioridade da personagem, que não pode ser questionado ou influenciado pelas situações externas de interlocução (Fig.27). Com essa significação, a autoridade do pai Polônio não provém de uma postura mais agressiva, como sugere a adaptação da East Press, e sim parece se edificar pela posse desse saber o qual os filhos não poderão contestar ou influenciar.

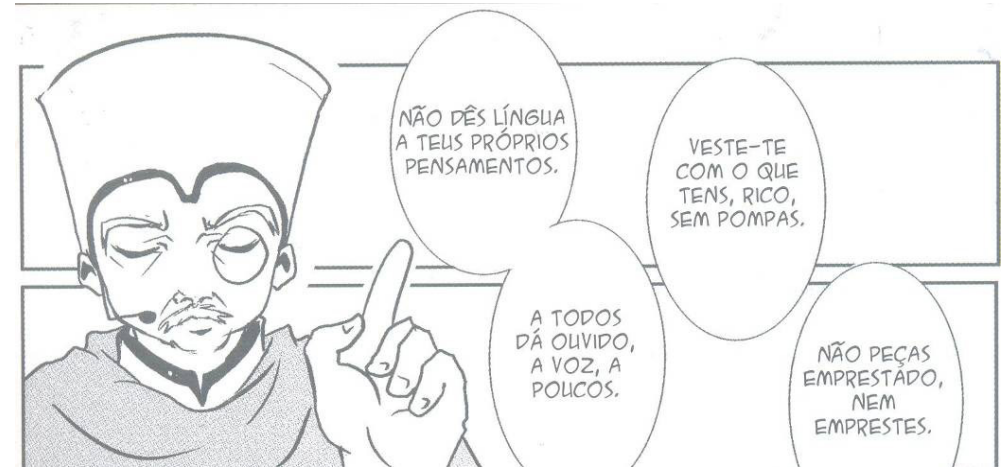

Fig.27. Adapt. Vieceli, p.45

Na adaptação de Grant e Mandrake, o olhar inquisidor do conselheiro Polônio em relação à sua filha Ofélia (Fig.28), ao invés de evoluir para uma cena de violento sermão ou de vaidade pela detenção de alguma sabedoria distante, retrata um semblante em que, ainda que o dedo esteja em riste, os olhos mais oblíquos traduzem uma preocupação paternal eivada de afetiva proteção (Fig.29).
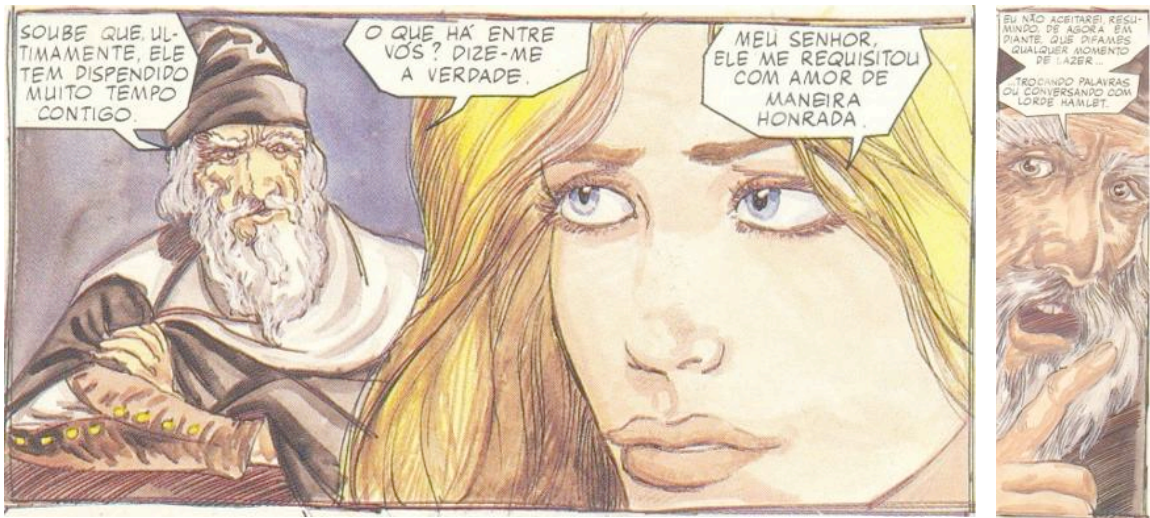

Fig.28. Adapt. Grant e Mandrake, p.10. Fig.29. Adapt. Grant e Mandrake, p.10. 
Em mais de um momento entre as cenas ilustradas por Tom Mandrake, essa impressão de controle paralela a uma demonstração de carinho é marcada. A recorrência dessa adaptação da aproximação tátil do conselheiro Polônio quanto aos seus filhos sugere o caráter afetuoso da função paterna. Nos quadros iniciais em que Polônio aparece, a sua mão fica numa posição às costas de Laertes, que sinaliza conforto e defesa ao filho perante a hierarquia do rei Cláudio (Fig.30). Em mais de um momento, Mandrake coloca as mãos de Polônio e de Ofélia unidas como um gesto de carinho enquanto conversam e a condução da caminhada do pai também representa, simbolicamente, a orientação moral necessária para a sua filha (Fig.31 e 32).
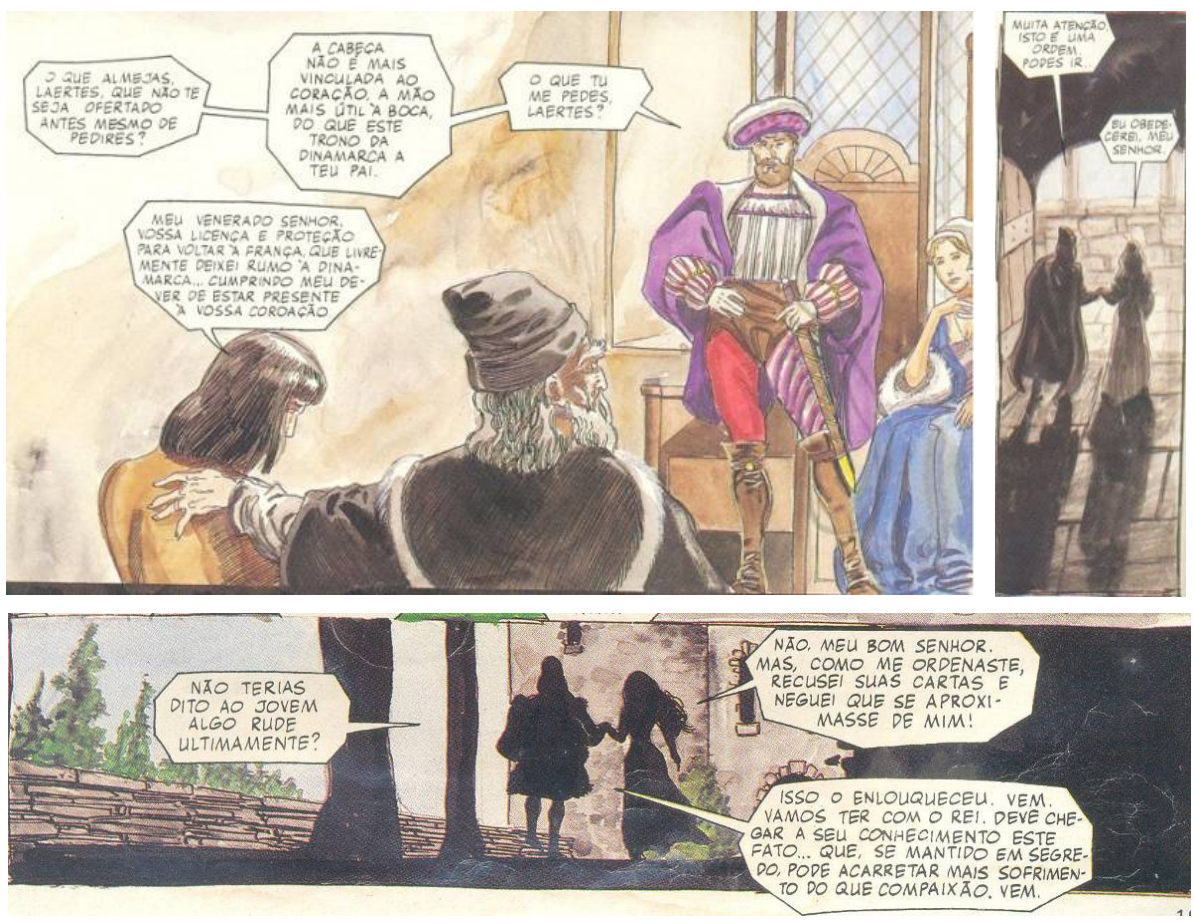

Fig.30. Adapt. Grant e Mandrake, p.5. Fig.31. Adapt. Grant e Mandrake, p.10. Fig.32. Adapt. Grant e Mandrake, p.15.

Na adaptação de Emma Vieceli, essa noção de pai protetor e afetuoso também aparece numa cena tensa, logo após Ofélia acabar de ser tratada ostensivamente por Hamlet ao mesmo tempo em que Polônio e o rei Cláudio estão escondidos e investigando o comportamento do príncipe. Assim que Hamlet retira-se e Ofélia fica só, o pai Polônio, preocupado, sai rapidamente de seu esconderijo para confortar a filha (Fig.33). Importante notar que tal gesto é uma interpretação de Vieceli, pois, nesse momento da peça de Shakespeare, Polônio concentra-se mais em dar uma explicação do ocorrido para o rei Cláudio que consolar a filha de uma situação difícil, ou seja, o acréscimo de Vieceli nessa 
cena distorce a ordem de prioridades para a personagem Polônio entre a função de servir o rei (mais urgente na peça) e a de ser um pai consolador (mais urgente na HQ).

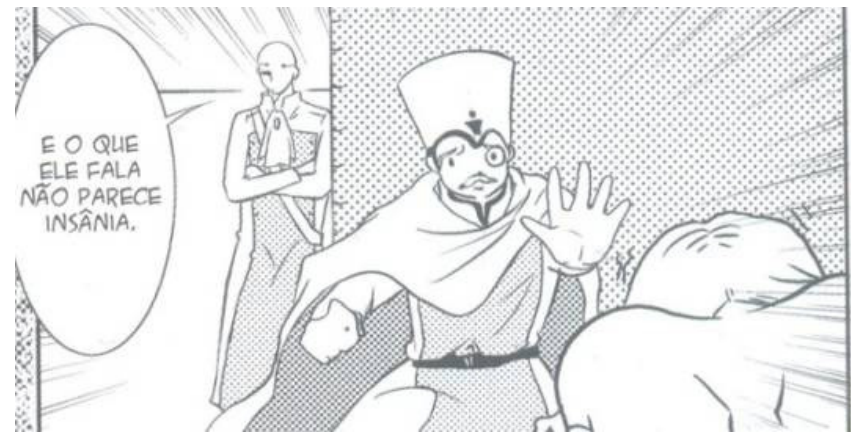

Fig.33. Adapt. Vieceli, p.101.

Polônio: Será bom. Mesmo assim, eu creio que a origem e o começo desse sofrimento têm raiz no amor não correspondido. Então, Ofélia? Não precisa dizer-nos o que o Senhor Hamlet disse. Ouvimos tudo. Meu Senhor, fazei como quiserdes, mas se julgares apropriado, depois da peça teatral, permiti que sua mãe-rainha o entretenha sozinha para mostrar-Ihe sua dor. Que ela seja franca com ele e eu ficarei, se for do vosso agrado, ouvindo toda a conversa. Se ela não descobrir seu secreto problema, mandai-o para a Inglaterra ou confinai-o lá onde vossa sabedoria aprouver. (SHAKESPEARE, 2003, p.129).

No entanto, a demonstração de afeição paterna chega ao ápice na adaptação de Grant e Mandrake quando o conselheiro e pai Polônio coloca a mão na face da filha Ofélia (Fig.34). O momento da cena é a fala de Ofélia acerca do momento em que notara a loucura no príncipe Hamlet. Quando o quadro da mão na face surge articulado com a fala de Polônio: "Louco por teu amor?", essa cena implica uma ambiguidade no sentido de se confundir a identidade de Hamlet (ser de desejo) e a identidade de Polônio (ser castrador). Se se levar em consideração a defesa de Ernest Jones (1970, p.135) de que o conselheiro Polônio estaria tomado pelo complexo de Griselda' ${ }^{1}$, pode-se chegar à interpretação desse quadro por meio da projeção de Polônio como o princípe Hamlet (louco de amor) ao tempo em que sublima seu próprio desejo de possuir a filha Ofélia. O olhar assustado de Ofélia também é de duplicidade: o susto pode provir do relato por ela contado a respeito da loucura de Hamlet ou da forma como o seu pai toca as mãos nela. Esse mesmo olhar surpreso e assustado sugere a ambígua interrogação: o que se passa com o comportamento do príncipe Hamlet? Ou o que se passa com o meu pai que me toca dessa maneira?

1 Ernest Jones (1970, p.135) propõe a hipótese de que o conselheiro Polônio esteja acometido pelo complexo de Griselda, ou seja, de acordo com o psicanalista, um desenvolvimento tardio do seu próprio complexo de Édipo original para com a mãe. Nesse sentido, o complexo de Griselda reflete o desejo da posse pelos órgãos sexuais da filha Ofélia (como projeção da mãe), retendo e combatendo os concorrentes (como tentativas de afirmações paternas) 


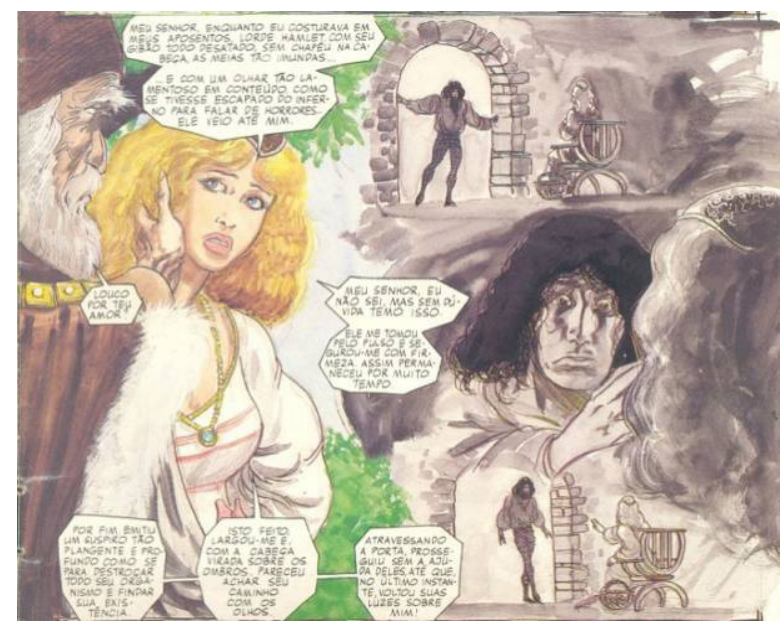

Fig.34. Adapt. Grant e Mandrake, p.15.

A ideia de projeção de Polônio como o ser desejoso de Hamlet parece ainda mais pertinente quando se observa que Mandrake cola duas imagens muito semelhantes entre o pai e o pretendente de Ofélia. Na ilustração à esquerda, Polônio toca a face da filha; na ilustração à direita, Hamlet realiza o mesmo gesto. Importante verificar que Tom Mandrake compõe tais momentos do desenho como um jogo de reflexos. A posição do olhar para o fundo do conselheiro Polônio surge, como no espelho da projeção almejada, no olhar para a frente do príncipe Hamlet - a face de Ofélia em posicionamentos opostos compõe um dos principais elementos que atribui a noção de reflexo ao espelho. Nesse sentido, o tom cinzento das ilustrações à direita pode sugerir dois sentidos. Um mais literal: a recordação de Ofélia sobre o encontro com o príncipe. E outro mais profundo: a projeção de Polônio ao fantasiar-se como Hamlet.

\section{Considerações finais}

Quando são analisadas as quatro adaptações da obra Hamlet, de Shakespeare, notam-se as peculiaridades de linguagens do gênero dramático e das HQs. Ainda que o gênero do teatro possa apontar para algumas facilitações quanto à construção do gênero quadrinhos, como o estudo do gesto no palco, é exatamente o oposto que se observa: essas marcações denotam limites de contato e diferenciações que multiplicam interpretações e releituras do texto em cena ou nos quadros das HQs. A capacidade de síntese nas falas e a projeção de uma dinâmica que envolve diálogos, expressões faciais e postura corporais em meio à natureza fixa dos desenhos nas HQs, em muito, distancia-se da possibilidade de fluidez simbiótica entre o texto do corpo e a retórica da fala a exibir-se no palco. 
Por outro lado, a multiplicidade de interpretações do texto dramático em cena sugere uma capacidade potencial de recriação que estimula o imaginário das transposições de uma obra como Hamlet em diversas perspectivas e sob diferentes suportes: filme, quadrinhos, pinturas, esculturas, etc. E tal variação quanto às possibilidades de releitura desse texto dramático aparece ainda mais pujante quando considerada a diversidade de obras a compor a fortuna crítica e a apontar para uma infinidade de versões interpretativas para cada personagem dessa obra. Desse modo, a variabilidade conceitual na composição de Polônio nas quatro adaptações estudadas não pode ser compreendida como um efeito negativo de infidelidade do texto dramático, mas como uma gestação incitada pela própria natureza ambígua do texto dramático shakespeariano, rico em fortuna crítica, em versões interpretativas singulares e em transposições para outros suportes.

Por mais que Will Eisner valorize a utilização dos estereótipos nas HQs como marcas fortes de tradução de caráter das personagens, é preciso notar que tais realizações nas quatro HQs tendem a traços que, por vezes, expressam conceitos próprios da personagem Polônio ora a convergir, ora a divergir entre si. Ademais, é importante observar o manancial de elementos e técnicas inusitados que foram incorporados à personagem do conselheiro Polônio pelos quadrinistas dessas quatro adaptações. Isso se deve ao fato de as adaptações em HQs, tal como comentado por Patrícia Pina, não serem transcrições do texto original, mas recriações (com leituras e propostas diversas) que distorcem, reformam, aglutinam e permitem a realização de uma história paralela de reconstrução e revivência do texto-fonte.

Thiago Martins Prado é doutor em Letras e professor do DCHT XXIII (Uneb-Seabra) e do Programa de Pós-Graduação em Estudo de Linguagens da Universidade do Estado da Bahia.

minotico@yahoo.com.br

\section{Referências}

AMORA, M. Hamlet, a difícil arte de decidir. Osasco, SP: Novo Século Editora, 2006.

BENJAMIN, W. Origem do drama barroco alemão. São Paulo: Brasiliense, 1984.

BLOOM, H. Hamlet, poema ilimitado. Rio de Janeiro: Objetiva, 2004.

EISNER, W. Narrativas gráficas. São Paulo: Devir, 2005.

FRYE, N. Sobre Shakespeare. São Paulo: EDUSP, 1992.

JONES, E. Hamlet e o complexo de Édipo. Rio de Janeiro: Zahar Editores, 1970.

MAZUR, D.; DANNER, A. Quadrinhos. São Paulo: WMF Martins Fontes, 2014.

MCCLOUD, S. Desenhando quadrinhos. São Paulo: M.Books do Brasil Editora, 2008. 
PINA, P. K. C. A literatura em quadrinhos. Rio de Janeiro: Dialogarts, 2014.

SHAKESPEARE, W. Hamlet. São Leopoldo: Editora Unisinos, 2003.

. Hamlet. Adaptação e ilustrações Equipe East Press. Porto Alegre, RS: L\&PM, 2013.

. Hamlet. Adaptação Steven Grant e Tom Mandrake. São Paulo: Abril Jovem, 1990.

. Hamlet. Ilustrações Emma Vieceli. Rio de Janeiro: Galera Record, 2011.

. Hamlet. Versão em quadrinhos por Wellington Srebk e Alex Shibao. São Paulo: Editora Nemo, 2013.

VYGOTSKY, L.S. A tragédia de Hamlet, príncipe da Dinamarca. São Paulo: Martins Fontes, 1999.

Artigo recebido em dezembro de 2016

e aprovado em maio de 2017. 